\title{
Relationship between the Tibetan Plateau heating and East Asian summer monsoon rainfall
}

\author{
Huang-Hsiung Hsu and Xin Liu \\ Department of Atmospheric Sciences, National Taiwan University, Taipei, Taiwan \\ Received 6 June 2003; revised 10 September 2003; accepted 29 September 2003; published 29 October 2003.
}

[1] This study reveals the close correspondence between the interannual variability of the dominant East Asian summer rainfall pattern and the diabatic heating over the Tibetan Plateau in both spring and summer. The heating fluctuation over the Tibetan Plateau is associated with two wave-like circulation patterns, which bear the characteristics of forced Rossby wave emanating away from the deep heating. The wave-like pattern in turn affects the East Asian summer rainfall. Because of the persistent heating over the Tibetan Plateau from spring to summer and its possible effect on the surrounding areas, the heating index defined in this study can be used as a good predictor for the JJA heating and precipitation distributions. Evidences shown suggest that external conditions other than the SST anomaly must be considered to understand the interannual variability of the East Asian summer rainfall. INDEX TERMS: 3319 Meteorology and Atmospheric Dynamics: General circulation; 3309 Meteorology and Atmospheric Dynamics: Climatology (1620); 3354 Meteorology and Atmospheric Dynamics: Precipitation (1854); 3322 Meteorology and Atmospheric Dynamics: Land/atmosphere interactions; 1620 Global Change: Climate dynamics (3309). Citation: Hsu, H.-H., and X. Liu, Relationship between the Tibetan Plateau heating and East Asian summer monsoon rainfall, Geophys. Res. Lett., 30(20), 2066, doi:10.1029/2003GL017909, 2003.

\section{Introduction}

[2] East Asian summer monsoon rainfall (EASMR) exhibits significant interannual variability. This variability is well correlated with the El Niño-Southern Oscillation [e.g., Tian and Yasunari, 1992; Weng et al., 1999; Lau and Weng, 2001]. Other studies found that the EASMR variability is associated with a north-south circulation oscillation called the Pacific-Japan pattern and suggested that this pattern is forced by the anomalous sea surface temperature (SST) in the tropical Western Pacific [Nitta, 1987; Lau, 1992; Huang and Sun, 1992]. It has also been suggested that the Tibetan Plateau (TP) heating effect might affect the EASMR. This factor has been included in the seasonal rainfall forecast procedure used by Chinese meteorological agencies. However, the possible link between the TP and the interannual EASMR variability is not as well studied as in the SST anomaly effect. This study reveals the close relationship between the TP heating and the EASMR and suggests that external conditions other than the SST anomaly should be considered to understand the interannual EASMR variability.

\section{Data}

[3] The monthly NCEP/NCAR reanalysis [Kalnay et al., 1996] from 1958-1997 were used in this study. The diabatic heating rate $H$, defined in the following equations, was estimated on a $1.875^{\circ} \times 1.875^{\circ}$ grid at $28 \sigma$ levels.

$$
Q(\sigma)=\mathrm{SH}(\sigma)+\mathrm{LH}(\sigma)+\mathrm{RD}(\sigma)
$$

where $\operatorname{SH}(\sigma)$ denotes the vertical diffusion heating rate, $\mathrm{LH}(\sigma)$ denotes the sum of latent heat released in deep and shallow convection and large scale condensation, and $\mathrm{RD}(\sigma)$ denotes the net radiative heating at every $\sigma$ level. The column heating is defined as

$$
H=\frac{c_{p} p_{s}}{g} \int_{0}^{1} Q(\sigma) d \sigma
$$

where $c_{p}$ is the specific heat at the constant pressure, $p_{s}$ is the surface pressure and $\mathrm{g}$ is the gravitational acceleration. An examination of the contribution from each heating component indicates that the column heating $H$ is dominated by the latent heating. Other NCEP data were used on a $2.5^{\circ} \times 2.5^{\circ}$ grid. The Climate Research Unit (CRU) precipitation data [New et al., 1999] used in this study covers only the land area on a $0.5^{\circ} \times 0.5^{\circ}$ grid. The data during the 1958-1996 period were used to match the NCEP reanalysis.

\section{Results}

[4] A heating index (hereafter referred to as HTP) was computed to represent the diabatic heating over the Tibetan Plateau. It is defined as the area average of the $H$ for those grid points where the altitude is above 3000 meters. One can also compute a similar index based on the precipitation. Our calculation indicates that the correlation between the two indices based on the heating and precipitation is about 0.4 , which is significant at the 0.01 significant level. The HTP represents the collective heating effect, while the precipitation could only reflect the amount of latent heat release. The HTP, which can be used as a forcing in the dynamical framework, is therefore chosen for this study.

[5] The June-August (JJA) time series shown in Figure 1a fluctuates between 60 and $140 \mathrm{Wm}^{-2}$ and exhibits multiple time scales. The inter-decadal fluctuation was marked by a dramatic shift in the late 1970s, which occurred concurrently with the well-documented climate regime shift. The HTP fluctuates between negative and positive values before the shift, but remains mostly positive afterward. The 

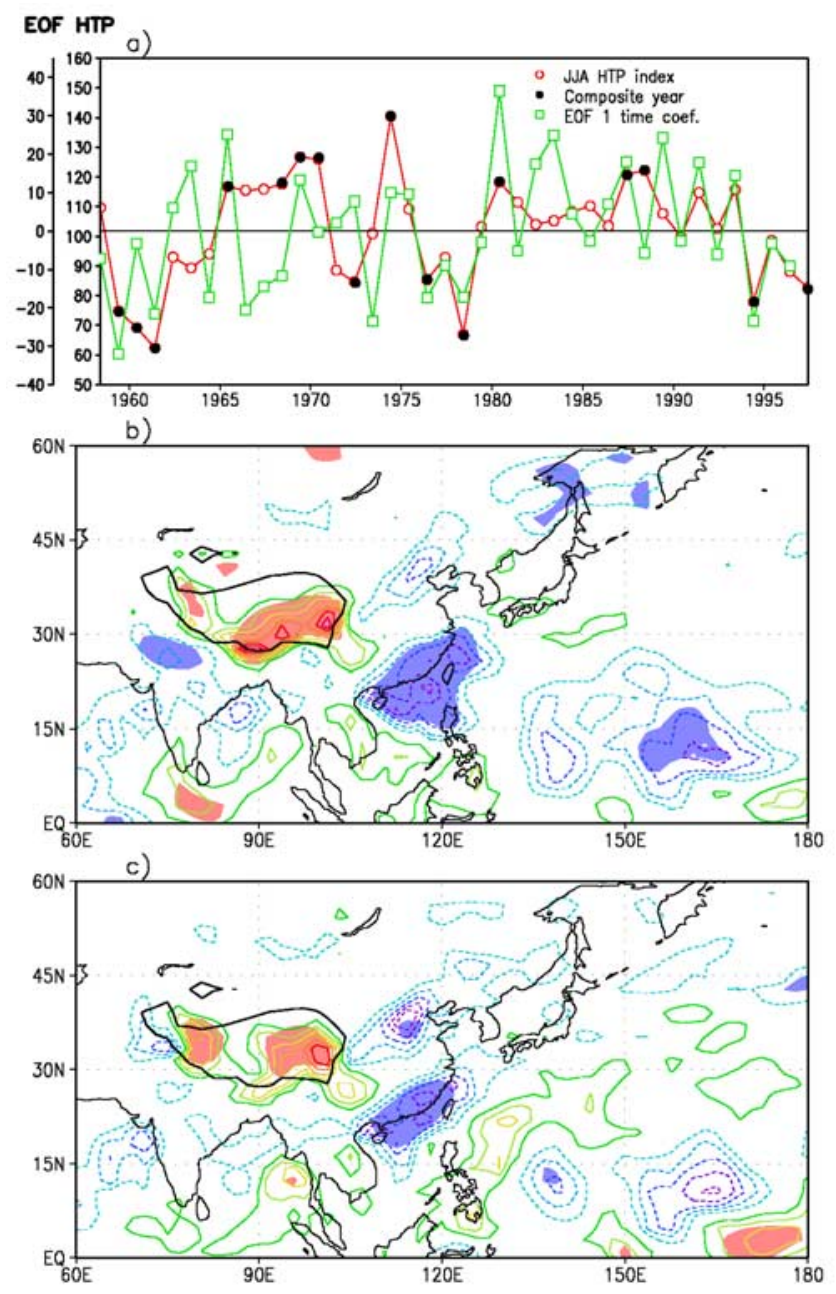

Figure 1. (a) Time series of the HTP and the first principle component corresponding to the EOF shown in Figure 2b. Difference of the JJA diabatic heating composites for (b) eight strong and weak HTP summers (JJA) and (c) four strong and nine weak HTP springs (MAM). Contour interval is $20 \mathrm{Wm}^{-2}$. Shading indicates the areas where the differences are statistically significant at the 0.05 significant level. Zero lines are not plotted. Solid and dashed lines denote positive and negative anomalies, respectively.

fluctuation before the shift exhibits larger amplitude and a longer period than its counterpart after the shift. Quasibiennial fluctuation is evident in the 1990's.

[6] Eight strong and weak heating summers with the JJA HTP anomalies larger than or equal to one standard deviation were chosen for composite purpose to reveal the relationship between the TP heating, the precipitation and circulation in East Asia. Figure 1b presents the differences between the diabatic heating composites for eight strong and weak cases. The result reveals that the index is highly correlated with the heating in the eastern TP. Negative anomalies are found in the surrounding areas with the largest signals in northern and southern China. A similar heating distribution, which is presented in Figure 1c, can be obtained if the MAM HTP is used as the index for composites. Similar distribution is also observed in the correlation maps between the HTP indices and the JJA diabatic heating at every grid point (not shown). The correlation coefficient between the JJA and MAM HTP indices is 0.62 . This high correlation and the great similarity between the JJA and MAM heating distributions suggest that, because of the persistent heating over the TP from spring to summer and its possible effect on the surrounding areas, the HTP can be used as a good predictor for the JJA heating distribution.

[7] Figure 2a presents the difference between the rainfall composites for the eight strong and weak JJA cases. This pattern exhibits a zonally elongated tripole structure with positive anomalies in central China, the southern Korean peninsula, and most areas of Japan, with negative anomalies in northern and southern China, Taiwan, and the northern Korean peninsula. The differences are larger than 100 percent in many areas. It means that the interannual variation associated with the strong and weak HTP years can be larger than the long-term climatological mean. Note that the negative rainfall anomalies correspond to the negative heating anomalies in northern and southern China. This good correspondence confirms the reliability of the diabatic heating derived from the NCEP reanalysis.

[8] This tripole pattern resembles the leading EOF rainfall pattern reported in previous studies [e.g., Tian and Yasunari, 1992; Nitta and Hu, 1996; Weng et al., 1999].

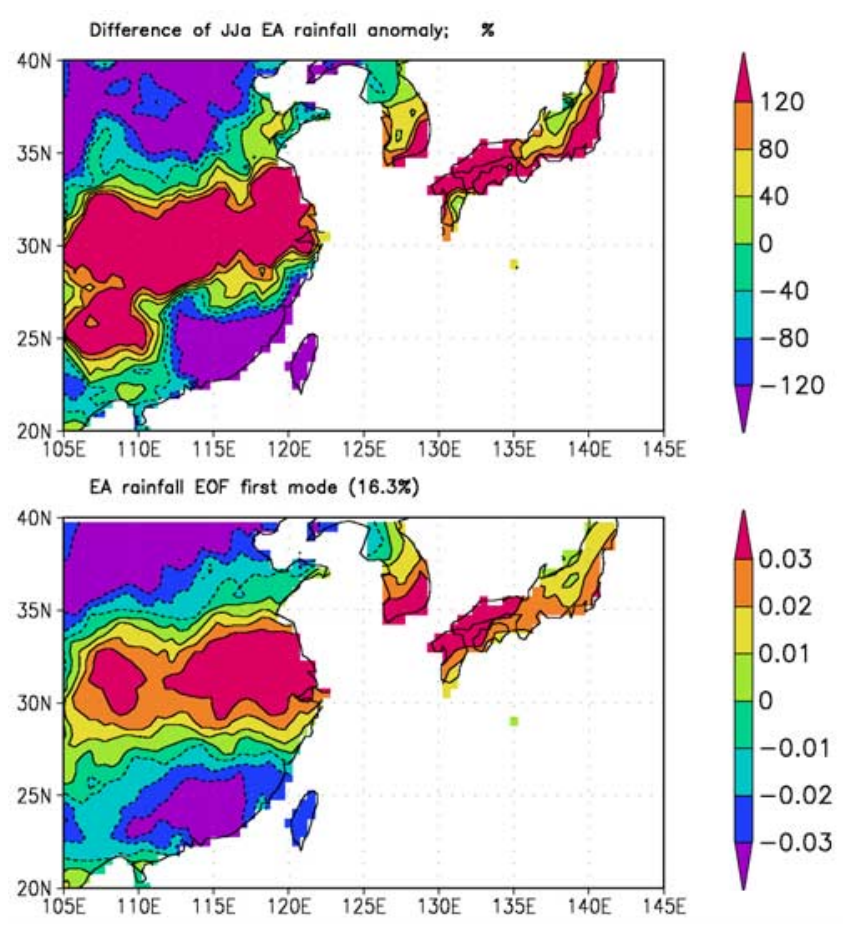

Figure 2. (a) Difference of the rainfall composites for eight strong and weak HTP summers. The percentage denotes the ratio of the difference to the long-term climatological mean. The contour interval is $40 \%$ and areas where values are larger than $120 \%$ and less than $-120 \%$ are shaded. (b) First EOF of the JJA rainfall. Contour interval is 0.01 and areas where values are larger than 0.025 and less than -0.025 are shaded. Zero lines in both (a) and (b) are not plotted. Solid and dashed lines denote positive and negative anomalies, respectively. 
o) $200 \mathrm{hPo} \quad\left(10^{-5} / \mathrm{s}\right)$

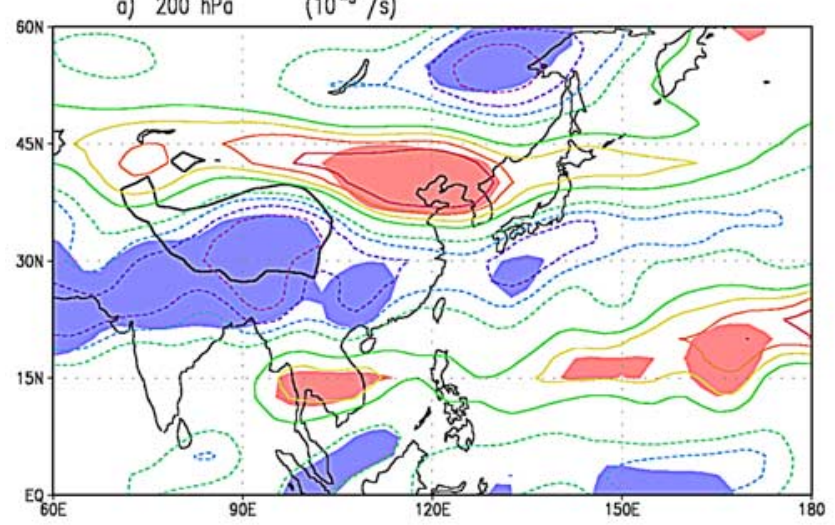

b) $500 \mathrm{hPo} \quad\left(10^{-5} / \mathrm{s}\right)$

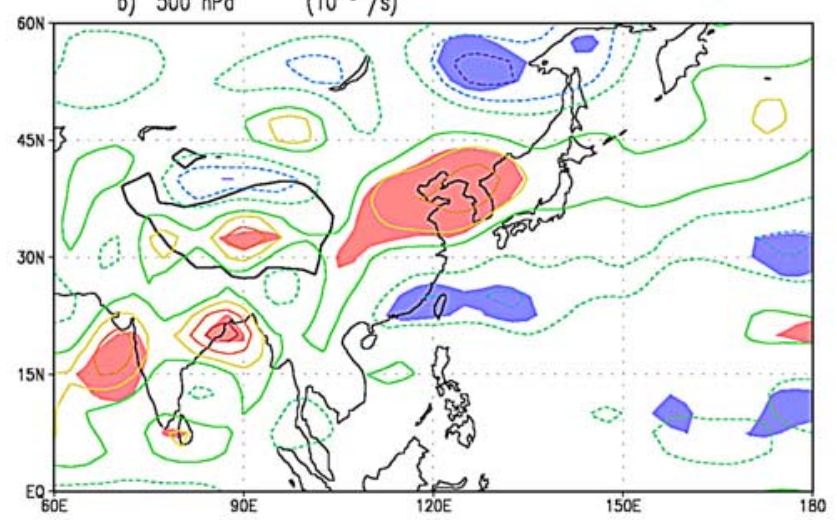

Figure 3. Difference of the (a) $200 \mathrm{hPa}$ and (b) $500 \mathrm{hPa}$ eddy vorticity (i.e., with zonal means removed) composites for eight strong and weak HTP summers. Contour interval is $0.2 \times 10^{-5} \mathrm{~s}^{-1}$. Shading indicates the areas where the differences are statistically significant at the 0.05 significant level. Zero lines are not plotted. Solid and dashed lines denote positive and negative anomalies, respectively.

A similar pattern is reproduced in Figure $2 b$, which is the first EOF of the JJA rainfall. The similarity between Figures $2 \mathrm{a}$ and $2 \mathrm{~b}$ is remarkable. This result suggests that the leading rainfall pattern embedded in the East Asian summer monsoon is closely associated with the diabatic heating over the TP. The corresponding principle component (PC) is shown in Figure 1a. Quasi-biennial oscillation is particularly evident in the first PC after 1980, a feature that has been reported in several studies [e.g., Shen and Lau, 1992; Tian and Yasunari, 1992]. The regime shift observed in the HTP time series is also evident in late 1970's. The similarity in the interannual and inter-decadal variations between the composite and EOF pattern reconfirms the close relationship between the TP heating and the EASMR.

[9] The corresponding vorticity anomalies with zonal means removed at 200 and $500 \mathrm{hPa}$ are shown in Figure 3. The pattern evidently consists of zonally-elongated and wave-like structures. At $200 \mathrm{hPa}$, two wave-like structures emanate northeastward and southeastward from the TP into the high latitudes and the tropics, respectively. This wavelike pattern was also documented by Liu et al. [2002]. A close examination between the rainfall and vorticity anomalies indicates that the positive and negative rainfall anomalies are located on the southern flank of the positive and negative vorticity anomalies, respectively. The large-scale circulation anomaly apparently modulates the interannual EASMR fluctuation.

[10] While the 200 and $500 \mathrm{hPa}$ anomalies exhibit the same signs in many areas, indicating an equivalent barotropic vertical structure, they exhibit opposite signs over the southern TP where the maximum heating is located, indicating a baroclinic vertical structure. The corresponding vertical structure and circulation along $90^{\circ} \mathrm{E}$ and $27.5^{\circ} \mathrm{N}-$ $32.5^{\circ} \mathrm{N}$ are shown in Figures $4 \mathrm{a}$ and $4 \mathrm{~b}$, respectively. The most significant upward motion anomaly is located at the southern TP along $90^{\circ} \mathrm{E}$ and the eastern TP along $27.5^{\circ} \mathrm{N}-$ $32.5^{\circ} \mathrm{N}$. Vorticity anomalies exhibit a baroclinic vertical structure near the updraft regions (i.e., the anomalous heating regions) and the equivalent barotropic vertical structure in the areas away from the TP. This spatial variation in the vertical structure and the two wave-like structures shown above are consistent with the forced Rossby wave characteristics from deep heating [Hoskins and Karoly, 1981]. Moreover, the relative spatial relationship between the anomalous heating and circulation shown

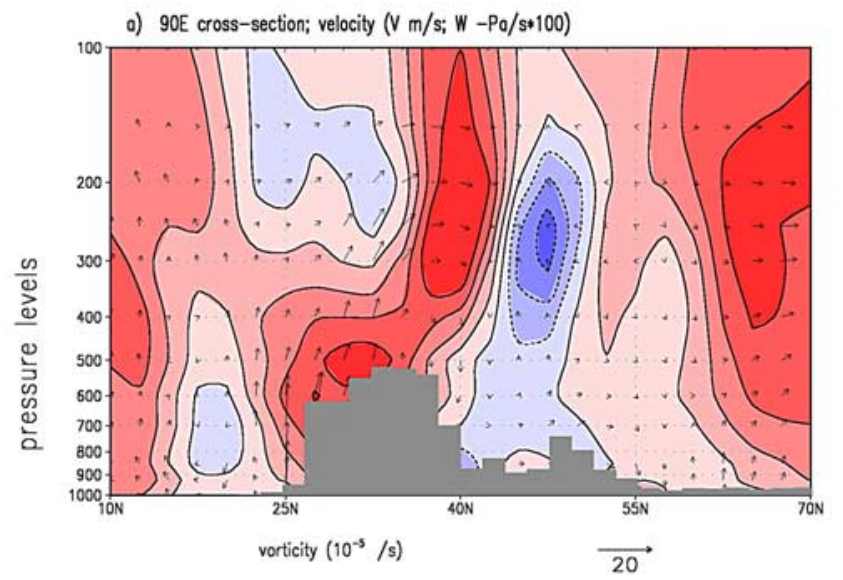

b) $27.5-32.5 \mathrm{~N}$ mean cross-section; velocity $\left(\mathrm{U} \mathrm{m} / \mathrm{s} ; \mathrm{W}-\mathrm{P}_{0} / \mathrm{s} \times 100\right)$

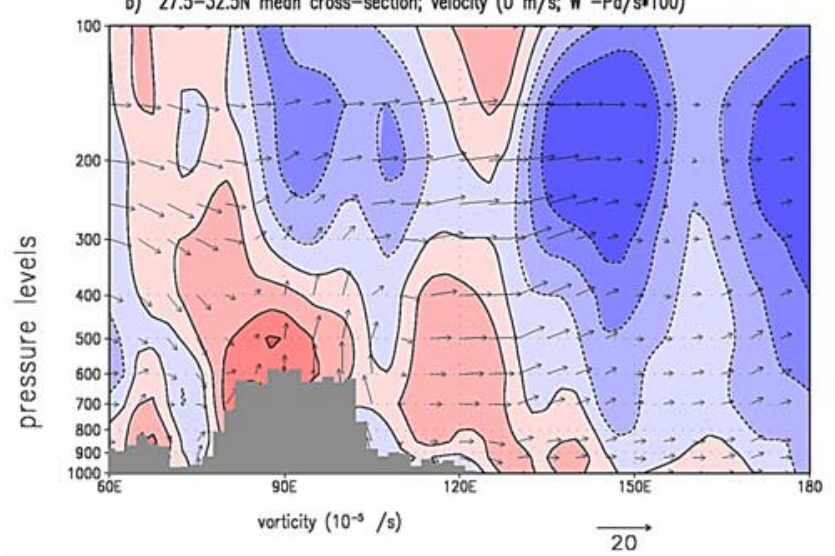

Figure 4. Cross section of the difference in the vertical circulation and vorticity composites for eight strong and weak HTP summers along (a) $90^{\circ} \mathrm{E}$ and (b) $27.5^{\circ} \mathrm{N}-$ $32.5^{\circ} \mathrm{N}$. The contour denotes vorticity and the vectors denote the vertical velocity and the meridional wind in (a) and the zonal wind in (b). The contour intervals and units are indicated in the figures. Solid and dashed lines denote positive and negative anomalies, respectively. 
in figures 2 and $3 \mathrm{a}$ is consistent with the suggestion by $W u$ et al. [2002] that a deep heating would force anticyclonic and cyclonic circulation in the upper troposphere to the west and east of a deep heating, respectively.

\section{Discussion and Concluding Remarks}

[11] The results presented above reveal the close relationship between the EASMR and the diabatic heating over the TP. It is proposed that the heating forces anomalous circulation propagating like a Rossby wave, which in turn affects the EASMR. This conjecture is supported by the following facts. First, the diabatic heating over the TP is a persistent feature lasting from spring to summer. Therefore, it is likely to be a forcing to the circulation rather than a response. Secondly, the spatial distribution of the vertical and horizontal structure exhibits forced Rossby wave characteristics from deep heating. In the mountain vs. no-mountain simulation, Hahn and Manabe [1975] found that one of the major effects of the TP is the existence of a realistic rain belt in East Asia in the mountain experiment. It is thus likely that the interannual fluctuation in the TP heating effect modulates the rainfall variability in East Asia. Nigam [1994] found that the orographically forced stationary waves in summer modulate the low-level moisture convergence in Indochina and East Asia. A recent numerical simulation study by Enomoto et al. [2003] found that the Bonin high affecting Japan in summer, which corresponds to the positive vorticity anomaly over Japan Sea in Figure 3, is mainly influenced by the diabatic heating fluctuation in the Eurasian continent rather than in the Tropical Western Pacific. These findings are consistent with the proposed conjecture. Further studies are needed to investigate whether the anomalous heating over the TP force the wave-like structure.

[12] However, the TP heating might not be the only and dominant forcing. A similar pattern was found correlated with the SST anomaly in the tropical Western Pacific [e.g., Nitta and Hu, 1996] and can be forced by the SST-induced convection anomaly in the tropical Western Pacific in numerical simulation [e.g., Kurihara and Tsuyuki, 1987]. Our results do not necessarily contradict these studies. The SST correlation, although statistically significant, is normally around $0.3-0.4$ and explains less than 20 percents of variance. It is likely that the dominant circulation pattern associated with the EASMR is affected by several factors. Normal-mode or nonmodal instability [Simmons et al., 1983; Newman et al., 1997] can be triggered by small perturbations, which may be forced by different types of boundary forcing (e.g., heating due to the anomalous SST in the tropical Western Pacific and/or the orographic effect of the TP). This view is consistent with the conclusion by Lau et al. [2000] that the zonally elongated rainfall pattern is the result of the interaction of the East Asian jet stream with the tropical convection and extratropical disturbances. The mechanism leading to the significant interannual variability of the EASMR can be quite complicated. It may involve the intrinsic instability and the ocean-atmosphere-land interaction. This study provides evidence to reiterate the important role of the atmosphere-land interaction in this complex framework.

[13] Acknowledgments. The authors appreciate the valuable comments of two anonymous reviewers. This study was supported by the National Science Council, Taiwan, under Grant NSC 91-2111-M-002-014.

\section{References}

Enomoto, T., B. J. Hoskins, and Y. Matsuda, The formation mechanism of the Bonin high in August, Q. J. R. Meteorol. Soc., 129, 157-178, 2003.

Hahn, D. G., and S. Manabe, The role of mountains in the South Asian monsoon circulation, J. Atmos. Sci., 32, 1515-1541, 1975.

Hoskins, B. J., and D. J. Karoly, The steady linear response of a spherical atmosphere to thermal and orographic forcing, J. Atmos. Sci., 38, 11791196, 1981.

Huang, R. H., and F. Y. Sun, Impacts of the tropical western Pacific on the East Asia summer monsoon, J. Meteorol. Soc. Japan, 70, 243-256, 1992.

Kalnay, E., M. Kanamitsu, R. Kistler, W. Collins, D. Deaven, L. Gandin, M. Iredell, S. Saha, G. White, J. Woollen, Y. Zhu, M. Chelliah, W. Ebisuzaki, W. Higgins, J. Janowiak, K. C. Mo, C. Ropelewski, J. Wang, A. Leetmaa, R. Reynolds, R. Jenne, and D. Joseph, The NCEP/NCAR 40-Year Reanalysis Project, Bull. Am. Meteorol. Soc., 77(3), 437-472, 1996.

Kurihara, K., and T. Tsuyuki, Development of the barotropic high around Japan and its association with Rossby wave-like propagations over the North Pacific: Analysis of August 1984, J. Meteorol. Soc. Japan, 65, 237-246, 1987.

Lau, K.-M., The East Asian summer monsoon rainfall variability and climate teleconnection, J. Meteorol. Soc. Japan, 70, 211-241, 1992.

Lau, K.-M., K.-M. Kim, and S. Yang, Dynamical and boundary forcing characteristics of regional components of the Asian summer monsoon, J. Clim., 13, 2461-2482, 2000.

Lau, K.-M., and H. Weng, Coherent modes of global SST and summer rainfall over China: An assessment of the regional impacts of the 1997-98 El Nino, J. Clim., 14, 1294-1308, 2001.

$\mathrm{Liu}, \mathrm{X} ., \mathrm{W}$. Li, and G. Wu, Interannual variation of the diabatic heating over the Tibetan plateau and the Northern Hemispheric circulation in summer, Acta Meteorol. Sinica, 60(3), 267-277, 2002.

New, M., M. Hulme, and P. Jones, Representing Twentieth-Century SpaceTime Climate Variability. Part I: Development of a 1961-90 Mean Monthly Terrestrial Climatology, J. Clim., 12, 829-856, 1999.

Newman, M., P. D. Sardeshmukh, and C. Penland, Stochastic forcing of the wintertime extratropical flow, J. Atmos. Sci., 54, 435-455, 1997.

Nigam, S., On the dynamical basis for the Asian summer monsoon rainfallEl Niño relationship, J. Clim., 7, 1750-1771, 1994.

Nitta, T., Convective activities in the tropical western Pacific and their impact on the Northern Hemisphere summer circulation, J. Meteorol. Soc. Japan, 65, 373-390, 1987.

Nitta, T., and Z.-Z. Hu, Summer climate variability in China and its association with $500 \mathrm{hPa}$ height and tropical convection, J. Meteorol. Soc. Japan, 74, 425-445, 1996.

Shen, S., and K.-M. Lau, Biennial oscillation associated with the East Asian summer monsoon and tropical sea surface temperature, J. Meteorol. Soc. Japan, 73, 105-124, 1992.

Simmons, A. J., J. M. Wallace, and G. Branstator, Barotropic wave propagation and instability, and atmospheric teleconnection patterns, J. Atmos. Sci., 40, 1363-1392, 1983.

Tian, S.-F., and T. Yasunari, Time and space structure of interannual variations in summer rainfall over China, J. Meteorol. Soc. Japan, 70, 585596,1992

Weng, H., K.-M. Lau, and Y. Xue, Multi-scale summer rainfall variability over China and its long-term link to global sea surface temperature variability, J. Meteorol. Soc. Japan, 77, 845-857, 1999.

Wu, G., L. Sun, Y. Liu, H. Liu, S. Sun, and W. Li, Impacts of land surface processes on summer climate, Selected Papers of the Fourth Conference on East Asia and Western Pacific Meteorology and Climate, edited by C.-P. Chang et al., World Sci., Singapore, 64-76, 2002 .

H.-H. Hsu and X. Liu, Department of Atmospheric Sciences, National Taiwan University, Taipei, Taiwan. (hsu@atmos1.as.ntu.edu.tw) 